\title{
Risk Factors Associated with Brucella Seropositivity in Sheep and Goats in Duhok Province, Iraq
}

\author{
Ali. G. Alhamada ${ }^{1,2,+}$ (D) Ihab Habib ${ }^{1,3, *,+}+{ }^{D}$, Anne Barnes ${ }^{1}$ and Ian Robertson 1,4 \\ 1 College of Veterinary Medicine, School of Veterinary and Life Sciences, Murdoch University, \\ Perth 6150, Australia; gaddan76@gmail.com (A.G.A); a.barnes@murdoch.edu.au (A.B); \\ i.robertson@murdoch.edu.au (I.R) \\ 2 College of Veterinary Medicine, University of Mosul, Mosul 41002, Iraq \\ 3 High Institute of Public Health, Alexandria University, Alexandria 21516, Egypt \\ 4 China-Australia Joint Research and Training Center for Veterinary Epidemiology, \\ Huazhong Agricultural University, Wuhan 430072, China \\ * Correspondence: i.habib@murdoch.edu.au; Tel.: +61-8-9360-2434 \\ + These authors contributed equally to this work.
}

Academic Editors: Chrissanthy Papadopoulou, Vangelis Economou and Hercules Sakkas Received: 23 October 2017; Accepted: 5 December 2017; Published: 7 December 2017

\begin{abstract}
Sera from 432 small ruminants (335 sheep and 97 goats) from 72 farms in Duhok Province, northern Iraq, were collected to investigate risk factors associated with brucellosis seropositivity. Serum samples were tested using the Rose Bengal test (RBT) and an indirect enzyme-linked immunosorbent assay (iELISA). Using parallel interpretation, RBT and iELISA results showed that $31.7 \%$ (95\% confidence interval (CI): $26.1,36.3)$ of sheep and $34.0 \%$ (95\% CI: $24.7,44.3)$ of goats had antibodies against Brucella in the study area. A random-effects multivariable logistic regression model indicated that a higher chance of being seropositive (odds ratio $(\mathrm{OR})=1.7 ; 95 \% 1.4 ; 2.2$ ) was associated with an increase in the age of animals. The odds of Brucella seropositivity in flocks where sheep and goats grazed together was 2.0 times higher $(95 \%$ CI: $1.08 ; 3.9)$ compared to flocks where sheep and goats grazed separately. The odds of Brucella seropositivity in small ruminants was 2.2 higher (95\% CI: 1.2; 4.3) for animals originating from farms with a history of goat abortion in the preceding 12 months. In contrast, for every 1000 Iraqi Dinars ( 0.85 US Dollar) spent by the farmers on control of Brucella in their flocks, the odds of Brucella seropositivity decreased significantly $(\mathrm{OR}=0.9, p$-value $=0.021)$. The final model also indicated significant differences in Brucella seropositivity between the different districts of Duhok Province. This study provides a contribution to the epidemiology of brucellosis in small ruminants in northern Iraq.
\end{abstract}

Keywords: brucellosis; small ruminants; abortion; risk factors; Iraq

\section{Introduction}

Brucellosis is one of the most important types of zoonoses affecting both human and animal health. The disease is endemic in many nations throughout the Middle East, Mediterranean regions, Central Asia, and Latin America. Brucella melitensis (mainly infecting sheep and goats) is the most common cause of human brucellosis worldwide [1]. In humans, the disease manifests with acute febrile illness which, if not treated adequately, might develop complications that include chronic hepatomegaly, splenomegaly, and arthritis. In livestock, brucellosis mainly affects the reproductive organs and causes abortion, reduced fertility, and decreased milk production [2]. Hence, the disease could have serious negative socio-economic impacts on people, especially in low-income countries, due to loss of work or income as a consequence of illness and reduced profitability in the livestock sector [3]. 
In Iraq, the small ruminant (sheep and goats) sector is very important for sustaining the country's food security. There are presently an estimated 7-8 million sheep and 1.5-2.0 million goats in Iraq, representing a valuable source of meat and milk production, and providing income and job security to people working across the agricultural sector [4]. An important challenge facing the small ruminant sector in Iraq is the challenging animal disease situation. Many endemic diseases are poorly managed and controlled as a consequence of the collapse of the veterinary infrastructure as a result of international economic sanctions and political and ethnic conflicts [5]. Among the many endemic animal diseases, Brucella melitensis continues to pose a threat to animal productivity and public health in Iraq. Jabary and Al-Samarraee [6] detected Brucella antibodies in 27.6\% of whole blood samples $(n=311)$ from small ruminants in the Al-Sulaimanya governorate (north of Iraq). Many factors may play a role in the spread and survival of Brucella among animals, including variation in flock or herd size, animal density, and livestock contact between flocks [6,7]. The incidence of Brucella melitensis in humans in Iraq has been estimated to be between 52.3 cases per 100,000 person-years in a rural area to 268.8 cases per 100,000 person-years in a semi-rural area [8]. Such wide variations in reported brucellosis incidence is evident between different governorates in Iraq, highlighting the need to deepen our understanding of risk factors for disease transmission at the human-animal interface.

Northern provinces of Iraq share extensive, however loose, borders with neighboring Turkey and Syria. Brucellosis control in northern Iraq is very challenging, as it demands coordinated regional control efforts with neighboring countries [9]. Such coordination of control efforts is overshadowed by the political instability across the borders. For instance, Duhok province, at the very north of Iraq, has received a major influx of immigrants and refugees from neighboring Syria and from other parts of Iraq over the last two years [10]. This human migration also involved the movement of an estimated 100,000 sheep and goats. These livestock are often sold cheaply, grazed illegally, and not vaccinated regularly [10]. In such a setting, local livestock might become more vulnerable to unprecedented exposure, which might facilitate spread and persistence of many diseases. Therefore, objectives of the present study were to estimate the current seroprevalence of Brucella among sheep and goats in Duhok in the north of Iraq, and to identify risk factors associated with seropositivity.

\section{Materials and Methods}

\subsection{Study Area and Population Included}

Duhok province is located in the northern part of Iraq, and borders Syria and Turkey. The province is populated by approximately 1.2 million people, and contains about 1 million sheep and goats. Duhok is divided into seven districts, with each district being further subdivided into two sub-districts and a number of villages [11]. The study setting included six of the seven districts of Duhok; it was not possible to access one of the districts due to security concerns. The study was conducted between February and April 2016, preceding the governmentally subsidized Brucella vaccination campaign in the region, and thus omitting any biased seropositivity due to vaccination.

Duhok contains a large area of pastures, and sheep and goats are either grazed separately or together under a communal grazing system. Grazing of livestock is usually overseen by the farmers themselves or by shepherds employed by the farmers. A shepherd may be responsible for a large number of sheep and goats belonging to different owners. In this study, only flocks managed directly by farmers were included to ensure the accuracy of the questionnaire information. Flocks with a minimum of 100 animals (typical flock demographics in the study area) were eligible for inclusion in this study.

\subsection{Sampling Strategy}

There was no sampling frame available from the local veterinary office. Hence, we adopted a convenient two-stage sampling approach, based on a participatory approach with the help of local farmers' knowledge and networks. We do realize that this might have affected the representativeness of the study population; however, such a limitation is inherently imposed by the immense logistical 
challenges of the field work area in Northern Iraq. All of the 12 sub-districts of the 6 surveyed districts in Duhok province were included in this study. Local community leaders in each district were approached at the central mosque, and were asked to voluntarily provide information about the farmers within the target sub-district who raised sheep and goats, and who met the inclusion criteria set for sampling (excluding shepherd-managed flocks, and excluding farms with $<100$ animals). From each sub-district, all farms meeting the study inclusion criteria for sampling (typically 2-3 farms), and whose owners agreed to participate in the study, were visited. A total of 432 individual blood samples (335 sheep and 97 goats) were collected. From each farm, six individual animals were randomly selected (random walk (every 10 steps, an animal was pointed at and then picked by farmer and taken to a holding pen)) for collection of blood samples. For mixed flocks, three sheep and three goats were sampled per farm. As mentioned before, sampling was achieved without probability proportional to size due to absence of farm registries in such remote study area. At the time of sampling, a questionnaire about the flock's health and management was administered to the farmer.

A questionnaire was administered through a face-to-face interview to the selected farmers. The questionnaire was developed in English then translated into Kurdish and administered to the farmers by a native-speaking Kurd. Information was gathered about the management and husbandry practices adopted, flock make-up, and history of abortions in the relevant flocks (Tables 2 and 3).

\subsection{Serological Analyses}

Serum was extracted from whole blood by centrifugation at $3000 \mathrm{rpm}$ for $10 \mathrm{~min}$ and stored at $-20^{\circ} \mathrm{C}$ until testing. Each serum sample was screened for anti-Brucella antibodies using the Rose Bengal Test (RBT; VIRCELL, Granada, Spain) and commercial ELISA (NovaTec, Dietzenbach, Germany). The RBT was conducted according to the manufacturer's protocol. Sera from sheep and goats were tested for anti-Brucella IgG antibodies using ELISA kits according to the manufacturer's instructions and the recommended cut-off titer level. Testing was carried out in a nationally accredited commercial laboratory in Duhok. The serological status for given sera was given by a parallel test interpretation of the results of the two tests. Thus, serum was regarded as serologically positive when a positive result was recorded on one or both of the tests.

\subsection{Statistical Analyses}

The binary serological results (seronegative $=0$ /seropositive $=1$ ) and variables on the characteristics of flock's health and management, explained in the previous section, were recorded for all animals sampled for the study. The data were entered into an Excel spreadsheet and analyzed using STATA (Version 11.2, StataCorp, College Station, TX, USA). To account for the effect of the farms (categorical variable identifying the group structure) as a potential cluster variable, random-effects logistic regression models were used to assess the association between brucellosis seropositivity and predictor factors. The analysis was conducted in two steps. Firstly, the association between putative predictor factors (independent variables) and the dependent variable (Brucella seropositivity) was initially assessed using univariate logistic regression analysis to quantify the strength of association between the independent variables and Brucella seropositivity. The second stage in the analysis consisted of building a multivariable logistic regression model based on potential risk factors identified from the univariate analysis, with factors with a $p$-value $\leq 0.25$ in the univariable analysis retained in the multivariable model. The most appropriate final model was selected using a backward stepwise selection approach. All pairwise interactions between the variables in the final model were examined for significance. Goodness of fit of the final model was assessed using the Hosmer-Lemeshow test. The associations between brucellosis seropositivity and putative risk factors were considered significant at a $p$-value $\leq 0.05$, and were assessed using odds ratios (ORs) and $95 \%$ confidence intervals (CIs). 


\subsection{Ethical Approval}

The study had been approved by the animal and human ethics committees of Murdoch University, with the permit number: R2805/15. All procedures were explained to farmers and informed verbal consent was obtained from all participants prior to sampling and administering the questionnaire.

\section{Results}

The seropositivity in goats $(34 \%, 95 \%$ CI: $24.7,44.3)$ was similar to that of sheep $(31.7 \%, 95 \%$ CI: $26.1,36.3)(p=0.450)$. When a single test was used, only $71 / 137(51.8 \%)$ and 102/137 $(74.4 \%)$ were respectively classified as serologically positive by RBT and indirect enzyme-linked immunosorbent assay (iELISA) (Table 1). When the results of the two tests were interpreted in parallel, $137 / 432(31.7 \%$, 95\% confidence interval (CI): $26.1,36.3)$ sera were classified as serologically positive for antibodies against Brucella.

Table 1. Serological detection of antibodies to Brucella among 432 small ruminants (335 sheep and 97 goats) from Duhok Province (Iraq) using the Rose Bengal test (RBT) and indirect enzyme-linked immunosorbent assay (iELISA).

\begin{tabular}{cccccccc}
\hline & \multicolumn{3}{c}{ Sheep } & \multicolumn{3}{c}{ Goats } \\
\hline & ELISA (-) & ELISA (+) & TOTAL & & ELISA (-) & ELISA (+) & TOTAL \\
\hline RBT (-) & 231 & 52 & 283 & RBT (-) & 64 & 14 & 78 \\
RBT (+) & 25 & 27 & 52 & RBT (+) & 10 & 9 & 19 \\
& 256 & 79 & 335 & & 74 & 23 & 97 \\
\hline
\end{tabular}

(+) positive; (-) negative.

The results from the questionnaire and the corresponding serological results are summarized in Tables 2 and 3 for categorical and continuous variables, respectively. Based on the univariate logistic regression analysis, the factors of age, districts, number of sheep per farm, number of goats per farm, flock grazing pattern, number of aborted goats on the farm during the preceding 12 months, farmer handling of aborted animals, sources of water on the farm, cleaning of water troughs, availability of agricultural workers on the farm, number of agricultural workers on the farm, and amount of money spent in flock on the control of Brucella in the preceding 12 months had a $p$ value $<0.25$, and were offered for the final random-effects multivariable logistic regression analysis (Table 4). The multivariable model indicated that none of the two-way interactions were statistically significant $(p>0.05)$. The Hosmer-Lemeshow test showed value of $3.065(p=0.930)$, which indicates a good fit of the model.

From the final model (Table 4), it could be suggested that the odds of brucellosis seropositivity were significantly higher with increasing age of animals (OR $=1.7 ; 95 \%$ CI: 1.4, 2.1). In addition, seropositivity among animals sampled from three districts was significantly lower (Amadiya (OR $=0.4$; 95\% CI: 0.1, 0.8), Duhok (OR = 0.3; 95\% CI: 0.1, 0.7), and Shekhan (OR = OR $=0.4 ; 95 \%$ CI: $0.1,0.8)$ ) as compared to those from Aqarh (Table 4).The final multivariable logistic regression model indicated that the odds of seropositivity were 2 times $(95 \%$ CI: 1.1, 3.9) higher for animals from flocks which grazed sheep and goats together, as compared to animals from flocks that did not graze sheep and goats together. Also, for goats on farms with abortions occurring in the 12 months preceding the survey, the odds for brucellosis seropositivity were 2.2 times (95\% CI: 1.2, 4.3) higher compared to those from farms with no reported abortions in goats in the preceding 12 months (Table 4). For every 1000 Iraqi Dinars ( 0.85 US Dollar) spent in the preceding 12 months to the survey on control of Brucella in small ruminant flocks in the study area, the odds of brucellosis seropositivity decreased significantly (OR $=0.93 ; 95 \%$ CI: 0.88, 0.98) (Table 4). 
Table 2. Categorical risk factors associated with brucellosis seropositivity among small ruminants from Duhok Province (Iraq) using parallel interpretation of the Rose Bengal test (RBT) and indirect enzyme-linked immunosorbent assay (iELISA).

\begin{tabular}{|c|c|c|c|}
\hline Variables & Category & $n$ & Seropositivity (\%) \\
\hline \multirow{6}{*}{ District } & Aqarh & 72 & 54.1 \\
\hline & Amadiya & 72 & 22.2 \\
\hline & Duhok & 72 & 20.8 \\
\hline & Simele & 72 & 36.1 \\
\hline & Shekhan & 72 & 26.4 \\
\hline & Zakho & 72 & 38.9 \\
\hline \multirow{2}{*}{ Species } & Sheep & 335 & 31.0 \\
\hline & Goats & 97 & 34.0 \\
\hline \multirow{2}{*}{ Sex } & Male & 45 & 28.1 \\
\hline & Female & 387 & 32.0 \\
\hline \multirow{2}{*}{$\begin{array}{l}\text { Sheep vaccinated against Brucella in the } \\
\text { preceding } 12 \text { months }\end{array}$} & Yes & 211 & 31.1 \\
\hline & No & 124 & 32.7 \\
\hline \multirow{2}{*}{$\begin{array}{l}\text { Goats vaccinated against Brucella in the } \\
\text { preceding } 12 \text { months }\end{array}$} & Yes & 53 & 30.5 \\
\hline & No & 44 & 32.5 \\
\hline \multirow{2}{*}{ Flock grazing pattern } & Sheep and goats graze together & 252 & 33.3 \\
\hline & Sheep and goats graze separately & 180 & 30.5 \\
\hline \multirow{2}{*}{$\begin{array}{l}\text { Flock grazing-Mixing of flocks from } \\
\text { different farms }\end{array}$} & Yes & 240 & 31.6 \\
\hline & No & 192 & 31.7 \\
\hline \multirow{2}{*}{$\begin{array}{l}\text { Occurrence of abortion among animals } \\
\text { on the farm in the preceding } 12 \text { months }\end{array}$} & Yes & 228 & 35.5 \\
\hline & No & 204 & 27.4 \\
\hline \multirow{4}{*}{ Farmer handling of aborted animals } & Burning & 6 & 50.0 \\
\hline & Given to dogs & 348 & 33.9 \\
\hline & Thrown in public garbage & 42 & 21.4 \\
\hline & Thrown into open water canals & 36 & 19.4 \\
\hline \multirow{2}{*}{$\begin{array}{l}\text { Purchase (introduction) of new animals } \\
\text { for the farm in the preceding } 12 \text { months }\end{array}$} & Yes & 120 & 33.3 \\
\hline & No & 312 & 31.1 \\
\hline \multirow{4}{*}{ Sources of water on the farm } & River & 66 & 33.3 \\
\hline & Well & 132 & 31.8 \\
\hline & Spring & 108 & 43.6 \\
\hline & Tap water & 126 & 29.3 \\
\hline \multirow{3}{*}{ Water delivered to animals through: } & Concrete troughs & 36 & 30.5 \\
\hline & Metal troughs & 396 & 31.8 \\
\hline & Wooden troughs & 0 & 0 \\
\hline \multirow{2}{*}{ Cleaning of water troughs } & Yes & 420 & 31.0 \\
\hline & No & 12 & 58.3 \\
\hline \multirow{2}{*}{$\begin{array}{l}\text { Sharing of water sources by sheep and } \\
\text { goats with others from nearby farms }\end{array}$} & Yes & 198 & 26.3 \\
\hline & No & 234 & 36.3 \\
\hline \multirow{5}{*}{ Feed delivered to animals through: } & Concrete troughs & 36 & 22.2 \\
\hline & Metal troughs & 360 & 32.7 \\
\hline & Wooden troughs & 18 & 33.3 \\
\hline & Foraging & 12 & 41.6 \\
\hline & Tires & 6 & 0 \\
\hline \multirow{2}{*}{ Electricity on farm } & Yes & 204 & 29.1 \\
\hline & No & 228 & 33.3 \\
\hline \multirow{2}{*}{$\begin{array}{l}\text { Availability of employed agricultural } \\
\text { workers on the farm }\end{array}$} & Yes & 33.3 & 27.1 \\
\hline & No & 66.7 & 34.1 \\
\hline
\end{tabular}


Table 3. Continuous risk factors associated with brucellosis seropositivity among small ruminants from Duhok Province (Iraq) using a parallel interpretation of the Rose Bengal test (RBT) and indirect enzyme-linked immunosorbent assay (iELISA).

\begin{tabular}{lcc}
\hline \multicolumn{1}{c}{ Variable } & $\begin{array}{c}\text { Seropositive } \\
\text { (Mean } \pm \text { SD) }\end{array}$ & $\begin{array}{c}\text { Seronegative } \\
\text { (Mean } \pm \text { SD) }\end{array}$ \\
\hline Age (months) & $4.6 \pm 1.7$ & $3.5 \pm 1.4$ \\
Number of sheep on the farm & $403 \pm 550$ & $533 \pm 504$ \\
$\begin{array}{l}\text { Number of goats on the farm } \\
\text { If mixed with other flocks while grazing-number of external flocks }\end{array}$ & $124 \pm 176$ & $94 \pm 139$ \\
Number of aborted sheep on farm during the preceding 12 months & $20 \pm 1.7$ & $2 \pm 1.6$ \\
$\begin{array}{l}\text { Number of aborted goats on farm during the preceding 12 months } \\
\text { Number of agricultural workers on the farm }\end{array}$ & $16 \pm 20.0$ & $20 \pm 33.2$ \\
$\begin{array}{l}\text { Amount of money spent on feed in the preceding 12 months } \\
\text { (in 1000 Iraqi Dinars) }\end{array}$ & $1.3 \pm 3.7$ & $2 \pm 4.1$ \\
$\begin{array}{l}\text { Amount of money spent on electricity in the preceding 12 months } \\
\text { (in 1000 Iraqi Dinars) }\end{array}$ & $70 \pm 9.3$ & $60 \pm 8.8$ \\
$\begin{array}{l}\text { Amount of money spent in flock on control of Brucella in the } \\
\text { preceding 12 months (in 1000 Iraqi Dinars) }\end{array}$ & $10 \pm 1.9$ & $16 \pm 3$ \\
\hline
\end{tabular}

Table 4. Multivariable logistic regression analysis of risk factors associated with brucellosis seropositivity among small ruminants from Duhok Province (Iraq). CI: confidence interval; OR: odds ratio; S.E: standard error.

\begin{tabular}{llcccc}
\hline & Variables & OR & $\mathbf{9 5 \%}$ CI & S.E. & $p$-Value \\
\hline Age (month) & & 1.7 & $(1.4,2.1)$ & 0.196 & $<0.001$ \\
\hline \multirow{4}{*}{ Aistrict } & Aqarh & 1.0 & - & - & - \\
& Amadiya & 0.4 & $(0.1,0.8)$ & 0.156 & 0.019 \\
& Duhok & 0.3 & $(0.1,0.7)$ & 0.145 & 0.012 \\
& Simele & 0.8 & $(0.4,1.8)$ & 0.335 & 0.670 \\
Number of sheep on the farm & Shekhan & 0.4 & $(0.1,0.8)$ & 0.156 & 0.019 \\
& Zakho & 1.4 & $(0.6,3.2)$ & 0.591 & 0.331 \\
\hline \multirow{2}{*}{ Flock grazing-Pattern } & Sheep and goats graze separately & 1.0 & - & - & - \\
& Sheep and goats graze together & 2.0 & $(1.1,3.9)$ & 0.684 & 0.028 \\
\hline $\begin{array}{l}\text { Abortion among goats on farm } \\
\text { in the preceding 12 months }\end{array}$ & No & 1.0 & - & - & - \\
\hline $\begin{array}{l}\text { Money spent (in 1000 Iraqi Dinars) on control of Brucella in the flock } \\
\text { in the preceding 12 months }\end{array}$ & & 0.9 & $(0.8,0.9)$ & 0.002 & 0.021 \\
\hline
\end{tabular}

\section{Discussion}

In Iraq, brucellosis is considered as one of the most important endemic zoonotic diseases [12]. The main objective of this study was to investigate risk factors associated with brucellosis seropositivity among small ruminants reared in Duhok, northern Iraq. Result from this work provides the first pilot screening for Brucella in small ruminants, and also provides a better epidemiological insight that could be utilized for better management of such an important disease in animal production in the study setting in Iraq.

Seropositivity through the combined results of RBT and iELISA was used as the outcome variable for modeling risk factors in the study setting. The two tests used in this study are convenient and have been shown to be suitable for field screening. Nevertheless, none of the two tests are considered to be gold standard test and the approach of parallel interpretation has been widely recommended $[13,14]$. Despite being regarded as very sensitive, RBT and iELISA might still suffer from false-positive reactions due to presence of Gram-negative bacteria closely related to Brucella [14]. In this study, 
we combined both tests to achieve a parallel interpretation for the results. Our results revealed that about $25-50 \%$ of sera showing antibodies against brucellosis would have been classified as seronegative in a single testing approach either by RBT or iELISA. Several studies indicated that RBT is more suited for detecting the IgG1 and IgM typically produced during acute brucellosis infection. On the other hand, iELISA is more suited for detecting IgG which becomes dominant in chronic brucellosis cases $[13,14]$. Our results show that iELISA classified almost $25 \%$ more sera as seropositive, suggesting the predominance of a chronic infection context. Hence, a combination of tests could improve surveillance certainty and provide more reliable results for effective diagnosis and control of brucellosis.

In our study, the multivariable model analysis identified the age of animals as a risk factor associated with brucellosis seropositivity. In line with our finding, previous studies found that age has been regarded as one of the intrinsic factors to influence brucellosis seropositivity $[15,16]$. This could be attributed to the biological fact that clinical disease mainly affects the actively producing animals, as compared to young animals which have not reached reproductive age [17].

Next to animals' age, the regression model indicated that brucellosis seropositivity was significantly higher among animals sampled from three of the districts (in Aqarh, Zakho, and Simele). Aqrah district, where $54.1 \%$ of the animals were seropositive, holds the main road for movement of animals and goods throughout the province. This might increase the likelihood of contact between local animals with others from different villages, and might cause an increase in the risk of transmission of Brucella. In addition, the three districts with significantly higher brucellosis seropositivity share the most borders with Syria, Turkey, and the Mosul province, where most of the uncontrolled movements of animals take place, provoked by war and political instability. Uncontrolled movement and smuggling of animals across borders could contribute to the spread and persistence of animal diseases in a regional context. In the neighboring country, Iran, Sharifi et al. [18] highlighted the importance of small ruminants with unknown history from neighboring countries, mostly from Syria, as a significant risk factor of seropositivity for Brucella in small ruminants.

In our study, brucellosis seropositivity was also found to be associated with sheep flock size, with mixed grazing between sheep and goats, and with history of goat abortion on a farm. The effect of flock size and mixed farming of multiple species on the risk of infections with contagious diseases has been well documented [19]. In our study area, the average size of sheep flocks was almost 4 times bigger than the average size of goat flocks. It could be hypothesized that the larger the flocks, the higher the chances for contact between individual animals, and in particular contact with an infected animal. Also, larger flocks will typically have greater chance of contracting other herds with subsequent transmission into the herd.

The use of communal pastures allows frequent contact between animals, and provides increased opportunity for environmental exposure to infectious materials, for instance arising from parturition. Previous studies have reported that contact between goats and sheep at the flock level was one of the most important risk factors for infection with Brucella [20,21]. Also, it has been documented that goats carry higher susceptibility to Brucella infection compared to sheep [22]. This is in line with our finding that abortion among goats on the farm in the preceding 12 months was a risk factor for brucellosis seropositivity in the current study setting. Abortion facilitates the release of an enormous number of microorganisms which can contaminate the environment and subsequently be ingested by at-risk healthy animals in the infected flock [23].

The regression model indicated that in the setting of Duhok, northern Iraq, for every 1000 Iraqi Dinar ( 0.85 US Dollar) spent by the farmers on control of Brucella in their flocks, the odds of Brucella seropositivity decreased significantly $(\mathrm{OR}=0.9, p$-value $=0.021)$. This finding warrants for further investigation in order to elucidate further such a putative relationship. Farmers and their families would benefit from spending on brucellosis control at the farm level, for example by reducing mortality and morbidity costs and by opening up new trade opportunities. In addition, there is an obvious human health impact from expenditure on controlling brucellosis infection in the livestock sector. 
In Mongolia, research has found that if the costs of mass vaccination of livestock against brucellosis were allocated to all sectors in proportion to the benefits, the intervention would be profitable and cost-effective for the agricultural and health sectors [24]. Moreover, in Iraq, there have been several remarkable achievements attributed to past mass vaccination campaigns. The most important outcome was the apparent decrease in incidence of human brucellosis, which declined to almost 17 cases /100,000 people in the middle and south of Iraq in 2009 compared with 27.23 cases / 100,000 in 2002 and 88.55 cases /100,000 in 1995 [25]. The positive results revealed a crucial need to continue vaccination procedures annually in order to reach the lowest possible incidence rate.

Despite the results of the study, some limitations were observed. First, there was the short period of field sampling, as this was concluded over 3 months. This was shorter than what we planned for initially, but we were forced to conclude the field research in a shorter time due to emerging security issues in the study area, which were beyond our control. Second, our inclusion criteria to sample from larger herds (at least 100 animals) could have impacted the seropositivity estimates. However, as this work is the first pilot study in the study area, we assume that targeting larger flocks was a reasonable starting point giving the immense challenges of field work in Northern Iraq and limitations in access to personnel support on the ground. Third, microbiological testing for confirming Brucella status was not possible to carry out under the study setting conditions, and certainly this could have helped to further confirm the status of the serologically-positive animals.

\section{Conclusions}

In this study we investigated risk factors for brucellosis seropositivity in small ruminates in Duhok province, northern Iraq, an area suffering from ongoing geopolitical and ethnic conflicts. This investigation revealed that the age of animals, districts from which animals are reared, sheep flock size, mixed grazing between sheep and goats, and history of goat abortion on farm in the preceding 12 months were independently associated with higher brucellosis seropositivity in small ruminants in the study area. The likelihood for seropositivity decreased with the increase of farmer' expenditure on control of Brucella in sheep flocks. Given that the estimate of expenditure was directly provided by farmers, the possibility for a recall bias should not be ignored. We tried to validate the data provided by farmers regarding their estimate of expenditure; however, this was not possible to validate due to an absence of record-keeping on farms. Although the presence of antibodies does not necessary mean that sheep and goats are infected, these pilot results indicate the abundant presence of brucellosis in the study setting in northern Iraq. This study should be considered as a contribution to the epidemiology of brucellosis in small ruminants in Iraq.

Acknowledgments: We would like to thank the livestock farmers and local veterinarians in Duhok who agreed to participate in this study for their cooperation and efforts in facilitating data collection. Ali. G. Alhamada is indebted to the research fund from the Ministry of Higher Education in Iraq through a Ph.D. scholarship grant.

Author Contributions: I.R., I.H. and A.B. designed the study; A.G.A. performed the field work and wrote the manuscript; I.H., I.R. and A.B. edited the manuscript.

Conflicts of Interest: The authors declare that there is no any actual or potential conflict of interests regarding the publication of this study.

\section{References}

1. Addis, M. Public Health and Economic Importance of Brucellosis: A Review. Public Health 2015, 5, 68-83.

2. De Figueiredo, P.; Ficht, T.A.; Rice-Ficht, A.; Rossetti, C.A.; Adams, L.G. Pathogenesis and Immunobiology of Brucellosis: Review of Brucella-Host Interactions. Am. J. Pathol. 2015, 185, 1505-1517. [CrossRef] [PubMed]

3. Benkirane, A. Ovine and caprine brucellosis: World distribution and control/eradication strategies in West Asia/North Africa region. Small Rumin. Res. 2006, 62, 19-25. [CrossRef]

4. Bechtol, D.; Carpenter, L.R.; Mosites, E.; Smalley, D.; Dunn, J.R. Brucella melitensis infection following military duty in Iraq. Zoonoses Public Health 2011, 58, 489-492. [CrossRef] [PubMed] 
5. FAO. Brucella melitensis in Eurasia and the Middle East. In FAO Animal Production and Health, WHO and OIE Technical Bulletin; FAO: Rome, Italy, 2009.

6. Jabary, O.M.; Al-Samarraee, L.A. Detection of Brucella antibodies of sheep and goats by using two serological tests in Al-Sulaimanya governorate. Iraqi J. Vet. Med. 2015, 39, 32-37.

7. Turgay, O.; Ahmed, C.J. The Prevalence of Brucellosis in Goat and Sheep Milk Samples in Duhok District. Indian Vet. J. 2016, 14, 3-14.

8. Yacoub, A.A.; Bakr, S.; Hameed, A.M.; Al-Thamery, A.A.; Fartoci, M.J. Seroepidemiology of selected zoonotic infections in Basra region of Iraq. East. Mediterr. Health J. 2006, 12, 112-118. [PubMed]

9. Karim, M.A.; Penjouian, E.K.; Dessouky, F.I. The prevalence of brucellosis among sheep and goats in northern Iraq. Trop. Anim. Health Prod. 1979, 11, 186-188. [CrossRef] [PubMed]

10. Abdul-Khaleq, D. The Great Goat Flood Refugee Livestock Causing Crisis in Dohuk. Available online: http:/ / www.niqash.org/en/articles/economy/3102/ (accessed on 15 May 2017).

11. Rahman, M.A.A.; Al-Dabbagh, S.A.; Al-Habeeb, Q.S. Health education and peer leaders' role in improving low vaccination coverage in Akre district, Kurdistan region, Iraq. East. Mediterr. Health J. 2013, 19, 125-129. [PubMed]

12. Refai, M. Incidence and control of brucellosis in the Near East region. Vet. Microbiol. 2002, 90, 81-110. [CrossRef]

13. Nielsen, K.; Samagh, B.S.; Stemshorn, B. Agglutination of Brucella abortus cells by sera from cattle experimentally infected with Escherichia coli. Vet. Microbiol. 1980, 5, 123-134. [CrossRef]

14. Weynants, V.; Gilson, D.; Cloeckaert, A.; Denoel, P.A.; Tibor, A.; Thiange, P.; Limet, J.N.; Letesson, J.J. Characterization of a monoclonal antibody specific for Brucella smooth lipopolysaccharide and development of a competitive enzyme-linked immunosorbent assay to improve the serological diagnosis of brucellosis. Clin. Diagn. Lab. Immunol. 1996, 3, 309-314. [PubMed]

15. Megersa, B.; Biffa, D.; Niguse, F.; Rufael, T.; Asmare, K.; Skjerve, E. Cattle brucellosis in traditional livestock husbandry practice in Southern and Eastern Ethiopia, and its zoonotic implication. Acta Vet. Scand. 2011, 53, 24. [CrossRef] [PubMed]

16. Chimana, H.M.; Muma, J.B.; Samui, K.L.; Hangombe, B.M.; Munyeme, M.; Matope, G.; Phiri, A.M.; Godfroid, J.; Skjerve, E.; Tryland, M. A comparative study of the seroprevalence of brucellosis in commercial and small-scale mixed dairy-beef cattle enterprises of Lusaka province and Chibombo district, Zambia. Trop. Anim. Health Prod. 2010, 42, 1541-1545. [CrossRef] [PubMed]

17. Amin, K.M.; Rahman, M.B.; Rahman, M.S.; Han, J.C.; Park, J.H.; Chae, J.S. Prevalence of Brucella antibodies in sera of cows in Bangladesh. J. Vet. Sci. 2005, 6, 223-226. [PubMed]

18. Sharifi, H.; Mashayekhi, K.; Tavakoli, M.M. Risk facts of small ruminant brucellosis: A cross-sectional study in Southeast Iran 2012. Hum. Vet. Med. 2015, 7, 42-45.

19. Salman, M.; Meyer, M. Animal Brucellosis, diseases caused by Brucella spp. Prev. Vet. Med. 1987, 4, 485. [CrossRef]

20. Al-Alousi, M.T. Survey of Brucellosis in sheep in Al-Anbar province. Al-Anbar J. Agric. Sci. 2008, 6, $271-275$.

21. Al-Majali, A.M.; Majok, A.A.; Amarin, N.M.; Al-Rawashdeh, O.F. Prevalence of, and risk factors for, brucellosis in Awassi sheep in Southern Jordan. Small Rumin. Res. 2007, 73, 300-303. [CrossRef]

22. Alton, G.G. Brucella melitensis. In Animal Brucellosis; Nielsen, K., Duncan, J.R., Eds.; CRC Press: Boca Raton, FL, USA, 1990; pp. 379-382.

23. Alton, G. An introduction to caprine brucellosis [Brucella melitensis]. In Proceedings of the International Conference on Goat Production and Disease, Tucson, AZ, USA, 10-15 January 1982.

24. Roth, F.; Zinsstag, J.; Orkhon, D.; Chimed-Ochir, G.; Hutton, G.; Cosivi, O.; Carrin, G.; Otte, J. Human health benefits from livestock vaccination for brucellosis: Case study. Bull. World Health Organ. 2003, 81, 867-876. [PubMed]

25. Mugabi, R. Brucellosis Epidemiology, Virulence Factors, Control and Molecular Targets to Prevent Bacterial Infectious Diseases. Master's Thesis, North Dakota State University of Agriculture and Applied Science, Fargo, ND, USA, 2012.

(C) 2017 by the authors. Licensee MDPI, Basel, Switzerland. This article is an open access article distributed under the terms and conditions of the Creative Commons Attribution (CC BY) license (http:/ / creativecommons.org/licenses/by/4.0/). 